\title{
Changes in gait patterns of adults and adolescents with cerebral palsy following single- event multilevel procedures in stiff knee gait at baseline
}

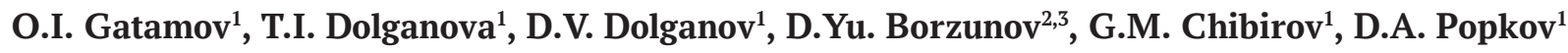 \\ ${ }^{1}$ Ilizarov National Medical Research Centre for Traumatology and Orthopedics, Kurgan, Russian Federation \\ ${ }^{2}$ Ural State Medical University, Ekaterinburg, Russian Federation \\ ${ }^{3}$ Central City Clinical Hospital, Ekaterinburg, Russian Federation
}

\begin{abstract}
The objective of this study was to evaluate outcomes of single-event multilevel orthopaedic procedures including distal rectus femoris transfer (DRFT) performed for adolescents and adults with cerebral palsy (CP) and stiff knee gait (SKG) pattern. Material and methods Twenty patients (mean age, $17.1 \pm 2.9$ years) with SKG were included in the study. Among them, 16 were classified as GMFCS level II and 4 as GMFCS level III. All patients underwent single-event multilevel orthopedic procedures including DRFT. Gait analysis was performed preoperatively and at a 1-to-2-year follow-up using Edinburgh Visual Gait Score and 3D analysis. The Gait Profile Score (GPS), peak knee flexion in swing phase, knee range of motion across the gait cycle and the maximum knee flexion angle recorded with the time of occurrence as a percentage of the gait cycle were measured in the patients. Results Comparison of pre- and postoperative measurements showed improvement in peak knee flexion in swing phase and the associated improvement in foot clearance. Improved knee terminal-swing position was found to improve initial foot contact with the supporting surface. Postoperative statistically significant increase in the knee range of motion across the gait cycle could be attributed to both increase in the knee flexion in swing phase and decrease in the knee flexion angle in stance due to correction of a pathological angle of dorsiflexion that necessitated correction of compensatory knee flexion to retain vertical position. Conclusion DRFT has been shown to be effective for correction of disturbed knee kinematics in patients with SKG pattern to allow increase in peak knee flexion in swing phase and overall knee range of motion across the gait cycle. The technique can be advocated as part of single-event multilevel orthopedic procedures to improve integral gait parameters. Excessive ankle dorsiflexion in stance phase resulting from previous triceps surae lengthening surgeries must be accurately addressed with DRFT procedure in order to prevent a greater increase in ankle dorsiflexion and iatrogenic crouch gait.

Keywords: cerebral palsy, single-event multilevel orthopedic surgery, stiff knee gait
\end{abstract}

\section{INTRODUCTION}

Stiff knee gait (SKG) is common among patients with spastic cerebral palsy and gross motor function classified as GMFCS levels I and II [1]. SKG is characterized by hyperactivity of the rectus femoris muscle at swing phase or constant rectus activity through the entire gait cycle [2]. It is also associated with diminished and delayed timing in peak knee flexion during swing and decrease in the knee range of motion across the gait cycle [3, 4]. Supported by computerized gait analysis surgical treatment involving distal rectus femoris transfer (DRFT) to the semitendinosus, the gracilis or the biceps femoris can help retain its function as hip flexor for early swing phase, reduce dysphasic extensor activity during swing and improve swing phase clearance $[4,5]$. Outcomes of the surgical procedure rely on kinematic gait assessment. Kinetic and electromyographic parameters add to characterization of the biomechanical aspects of the gait evaluated pre- and postoperatively [2, 6]. Treatment outcomes are often examined in the published literature as an effect from the surgical intervention [7-10]. Relatively few studies report on the outcomes of single-event multilevel orthopaedic procedures including DRFT [11-13].

The objective of this study was to evaluate outcomes of single-event multilevel orthopaedic procedures including distal rectus femoris transfer (DRFT) performed for adolescents and adults with CP and SKG pattern.

\section{MATERIAL AND METHODS}

The study comprised 20 patients (8 females and 12 males) who exhibited clinical signs of SKG that led to reduced foot clearance, excessive limb abduction with the progression of the leg into swing phase, compensatory straightening of the stance leg and heel rise in stance phase, positive $(++/+++)$ Duncan-Ely test (the hip of the tested side rising up from the table with the knee flexed less than $90^{\circ}$ ). Mean age of patients was $17.1 \pm 2.94$ years (range, 12 to 22 years). Gross motor function of 16 patients was classified as GMFCS level

[0] Gatamov O.I., Dolganova T.I., Dolganov D.V., Borzunov D.Yu., Chibirov G.M., Popkov D.A. Changes in gait patterns of adults and adolescents with cerebral palsy following single-event multilevel procedures in stiff knee gait at baseline. Genij Ortopedii, 2020, vol. 26, no 2, pp. 185-190. DOI 10.18019/1028-4427-2020-26-2-185-190 
II and the remaining 4 functioned at GMFCS level III. Soft tissue procedures performed for the patients earlier included fibromyotomy (one or two) $(\mathrm{n}=4)$, Achilles tendon lengthening $(n=6)$; the remaining patients underwent classical muscle-tendon surgeries: aponeurotomy with the Strayer procedure, lengthening of the medial hamstrings or the biceps femoris muscle.

All patients underwent single-event multilevel orthopedic procedures including DRFT. There were total 22 surgeries performed for the extensor apparatus of 38 femurs; two patients had surgeries produced on the limbs in a row. The distal tendon of the rectus femoris was transferred to the semitendinosus muscle tendon $(n=24)$, to the gracilis tendon $(n=6)$ and to the biceps femoris (the remaining segments). The most commonly used recipient tendon for the rectus femoris transfer was the semitendinosus muscle if it appeared to be intact from previous procedures. On average, an intervention consisted of 5.5 surgical components. The reason behind the highly concentrated surgery was the bilateral performance in the majority of cases. Surgical components of the procedures are presented in Table 1.

Gait analysis was arranged for all patients preoperatively and at a 1-to-2-year follow-up [14] using Edinburgh Visual Gait Score. Four patients underwent computerized gait analysis performed at the Ilizarov Gait Analysis Laboratory. Motion kinematic and kinetic analysis was produced with 6 Qualisys Oqus cameras and an AMTI (Advanced Mechanical Technology Inc., Watertown, MA) dynamometric platform using passive markers for video based motion capture.

Table 1

Components of surgical interventions
\begin{tabular}{|l|c|}
\hline \multicolumn{1}{|c|}{ Surgical component } & Number \\
\hline $\begin{array}{l}\text { Medial hamstring lengthening, tenotomy of } \\
\text { the m. gracilis }\end{array}$ & 12 \\
\hline Adductor lengthening & 4 \\
\hline $\begin{array}{l}\text { Aponeurotomy of the gastrocnemius, } \\
\text { Achilles tendon lengthening }\end{array}$ & 10 \\
\hline Shortening of the posterior tibial tendon & 6 \\
\hline Distal rectus femoris transfer & 38 \\
\hline Patellar realignment & 29 \\
\hline Detorsional osteotomy of the tibial bones & 4 \\
\hline Hallux valgus correction & 2 \\
\hline Achilles tendon shortening & 2 \\
\hline Talonavicular joint arthrodesis & 8 \\
\hline $\begin{array}{l}\text { Foot deformity correction with Evans } \\
\text { procedure }\end{array}$ & 4 \\
\hline Subtalar arthrodesis & 2 \\
\hline Total & 121 \\
\hline
\end{tabular}

Patients were asked to walk barefoot at their normal speed on a 7-meter track, supported by the hands, if needed. IOR design [15] was used when placing markers to facilitate slow speed walking and reduce skin marker artefact effects. The Gait Profile Score (GPS), peak knee flexion PKF) in swing phase, total knee range of motion (KROM) across the gait cycle and the maximum knee flexion angle recorded with the time of occurrence as a percentage of the gait cycle (time to PKF) were measured in the series. Statistical data analysis was performed using AtteStat 12.0.5 computer program and descriptive methods. The data obtained were summarized as means \pm standard deviations. The Wilcoxon signed-rank test was used to identify significant differences in scores measured with the Edinburgh Visual Gait Assessment.

The mean functional score for 17 items measured on the Edinburgh Visual Gait Assessment Scale is presented in Table 2. On the whole, kinematic gait parameters improved postsurgery throughtout the follow-up period.

Comparison of pre- and postoperative measurements showed improvement in peak knee flexion in swing phase and the associated improvement in foot clearance (Fig. 1). Improved knee terminal swing position facilitated better initial foot contact with the supporting surface. Whereas preoperative initial contact was produced either with the entire foot or the forefoot due to evident knee flexion prior to the stance phase, postoperatively, the improved knee extension resulted in initial contact produced either with the entire foot or the hindfoot. The corrected tibial torsion suggested adequate foot

orientation relative to the movement vector. At the same time evident delay in the heel lift during stance remained postsurgery due to weak triceps surae strength associated with earlier surgeries of fibromyotomy, Acilles tendon lengthening. Body balance showed no improvements in the frontal and sagittal planes after surgical treatment. Computerized gait analysis revealed improvements in kinematic parameters (Table 3).

Postoperative statistically significant increase in the knee range of motion across the gait cycle could be attributed to both increase in the knee flexion (Fig. 2) in swing phase and decrease in the knee flexion angle in stance due to correction of a pathological angle of dorsiflexion at the moment that necessitated correction of compensatory knee flexion to retain vertical position (Fig. 3). 
Table 2

The mean functional score measured on the Edinburgh Visual Gait Assessment Scale preoperatively and at a 1-to-2-year follow-up

\begin{tabular}{|l|c|c|}
\hline \multicolumn{1}{|c|}{ Items } & Pre-op & 1.5-to-2-year follow-up \\
\hline Initial contact & $1.0 \pm 0.51$ & $0.5 \pm 0.51$ \\
\hline Heel lift & $0.94 \pm 0.25$ & $0.93 \pm 0.26$ \\
\hline Maximum ankle dorsiflexion & $0.19 \pm 0.39$ & $0.09 \pm 0.17$ \\
\hline Hind-foot varus/valgus & $0.38 \pm 0.49$ & $0.36 \pm 0.49$ \\
\hline Foot progression angle & $0.75 \pm 0.84$ & $0.07 \pm 0.26$ \\
\hline Knee progression angle & $0.13 \pm 0.34$ & $0.0 \pm 0.0$ \\
\hline Peak knee extension & $0.06 \pm 0.25$ & $0.0 \pm 0.0$ \\
\hline Peak hip extension & $0.13 \pm 0.34$ & $0.14 \pm 0.36$ \\
\hline Pelvic obliquity at Mid-Stance & $0.75 \pm 0.67$ & $0.43 \pm 0.50$ \\
\hline Pelvic rotation at Mid-Stance & $0.31 \pm 0.59$ & $0.21 \pm 0.42$ \\
\hline Trunk Peak Sagittal Position & $0.63 \pm 0.49$ & $0.29 \pm 0.46$ \\
\hline Trunk maximum lateral shift & $1.5 \pm 0.72$ & $1.43 \pm 0.50$ \\
\hline Clearance & $1.2 \pm 0.51$ & $0.21 \pm 0.42$ \\
\hline Maximum ankle dorsiflexion & $0.61 \pm 0.59$ & $0.13 \pm 0.19$ \\
\hline Peak knee flexion & $1.4 \pm 0.65$ & $0.14 \pm 0.35$ \\
\hline Knee terminal swing position & $1.19 \pm 0.74$ & $0.18 \pm 0.39$ \\
\hline Peak hip flexion & $0.25 \pm 0.44$ & $0.0 \pm 0.0$ \\
\hline Total & $22.0 \pm 5.48$ & $9.79 \pm 2.83^{*}$ \\
\hline
\end{tabular}

Note: *- significant difference with the total baseline value measured with the Wilcoxon signed-rank test $(\mathrm{p}<0.05)$.

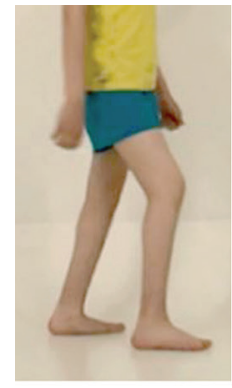

a

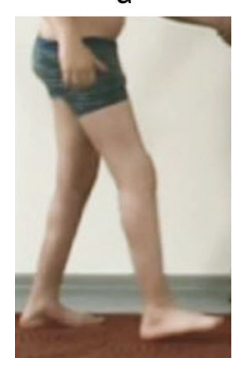

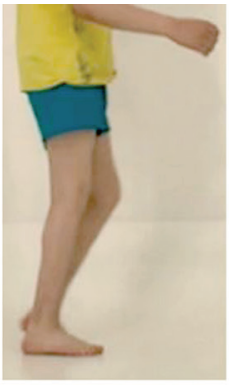

b

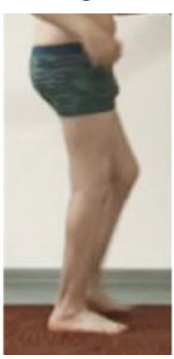

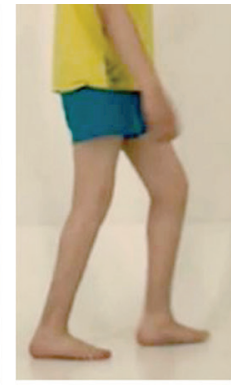

C

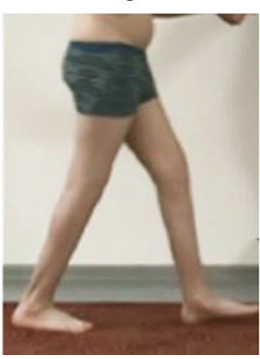

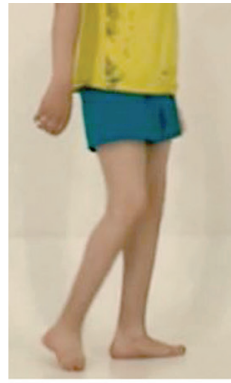

d

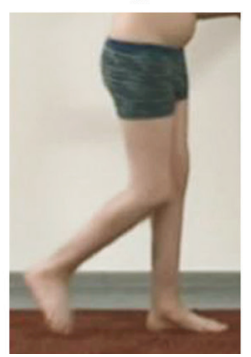

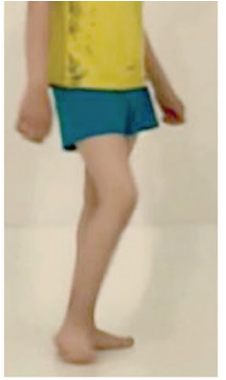

e

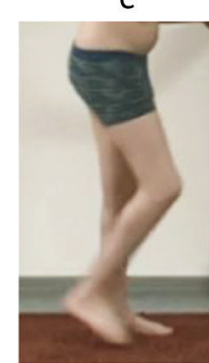

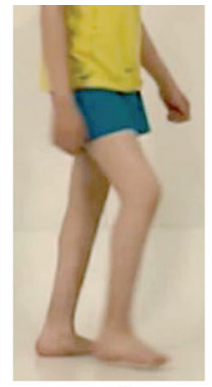

f

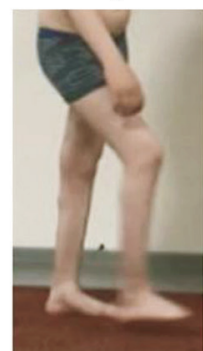

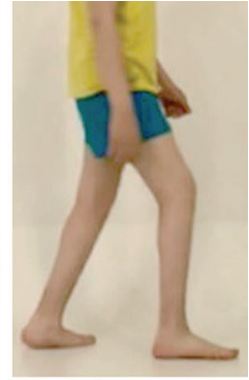

9

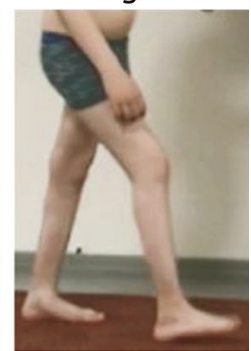

Fig. 1 Photographs showing gait of a 15-year-old patient K. with GMFCS level II preoperatively (upper row) and at a one-year follow-up (lower row): $(\boldsymbol{a})$ initial contact with the entire foot preoperatively, and with the hindfoot postsurgery; $(\boldsymbol{b})$ mid-stance with increased dorsiflexion pre-op; $(\boldsymbol{c})$ delayed heel lift throughout the whole period of obervation; (d) toe off, stride length increased postsurgery; $(\boldsymbol{e})$ foot clearance normalized at mid-swing postsurgery; $(\boldsymbol{f})$ position of the knee prior to the contact with the floor with less flexion seen postsurgery; $(g)$ initial contact with the entire foot pre-op, and with the hindfoot postsurgery

Table 3

Changes in kinematic characteristics measured at gait analysis laboratory

\begin{tabular}{|l|c|c|}
\hline & Pre-op & Post-op \\
\hline GPS & $14.2 \pm 2.8$ & $12.3 \pm 1.3$ \\
\hline PKF; ${ }^{\circ}$ & $44.2 \pm 6.7$ & $54.8 \pm 5.7$ \\
\hline \% PKF & $91.4 \pm 4.5$ & $81.6 \pm 3.1$ \\
\hline KROM; $^{\circ}$ & $21.3 \pm 10.4$ & $42.8 \pm 7.2^{*}$ \\
\hline
\end{tabular}

Note: * - significant difference with the total baseline value measured with the Wilcoxon signed-rank test $(\mathrm{p}<0.05)$. 
Knee Flexion (Flex +ve)

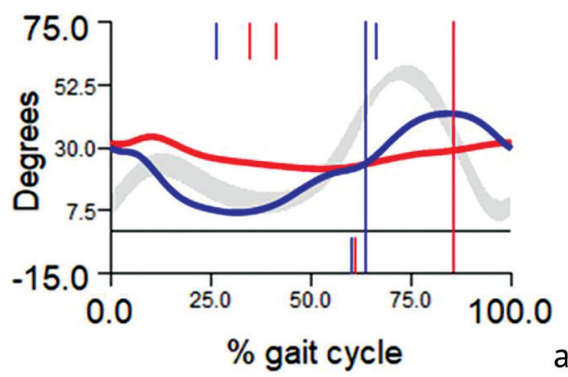

Knee Flexion (Flex +ve)

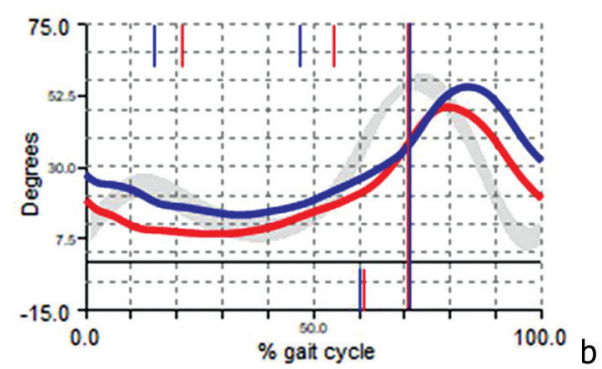

Fig. 2 Goniograms of the knee joint of a 17 -year-old patient $\mathrm{Kh}$. who underwent foot deformity correction with Evans procedure, shortening of the posterior tibial tendon in addition to DRFT showing: ( $\boldsymbol{a}$ ) preoperative peak knee flexion decreased in amplitude and delayed in time in swing phase, compensatory flexion of the left knee increased in stance phase with iatrogenic weakening of the triceps surae muscle; (b) postoperative increase in knee range of motion with peak knee flexion moment being still slightly delayed
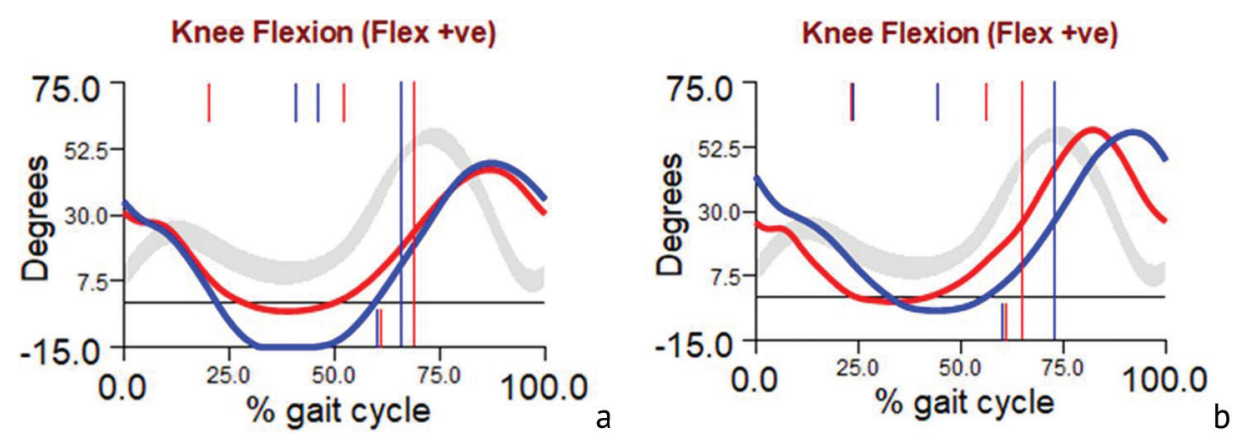

Fig. 3 Goniograms of the knee joint of a 14-year-old patient Sh. who underwent aponeurotomy with the Strayer procedure in addition to DRFT showing: $(\boldsymbol{a})$ preoperative peak knee flexion decreased in amplitude and delayed in time in swing phase, stance-phase recurvatum of the knee joints; $(\boldsymbol{b})$ postoperative knee range of motion nearly normalized with peak knee flexion moment being still slightly delayed on the right side

\section{DISCUSSION}

Current gait analysis techniques evaluating kinematic, kinetic and electromyographic parameters of muscle activity, dynamic angular changes and mechanical work of joints during gait cycle allow calculations of pathological values and patterns of gait in CP patients $[1,11,16]$. The technologies have been helpful in detection and quantitative description of the negative dominating effect of continuous rectus femoris activity throughout the swing phase that severely limits passive knee flexion and subsequent foot clearance [3-5]. DRFT to the hamstring tendons posteriorly to the knee joint axis enhances knee flexion in the swing phase compensating for decreased momentum of hip flexion to allow the $\mathrm{m}$. rectus femoris to be active for the first $20 \%$ of the swing phase [4, 17].

The surgical procedure allows improvements in peak knee flexion (PKF) in swing phase, knee range of motion (KROM) throughout the gait cycle and the maximum knee flexion angle (\% of PKF) [4, 9, 18]. Increase in PKF ranges from 1.2 to $17^{\circ}$ [2, $4,9,12,19]$. In our series, PKF increased by more than $10^{\circ}$ that is in line with the published data. There are controversies regarding dynamics in maximum swing-phase knee flexion at a long term. Saw et al. [19] found no changes in PKF at an average followup period of 4.6 years. Saraph et al. [20] reported $5^{\circ}$ decrease in PKF over 3 years. Thawrani et al. [2] reported decrease of $6^{\circ}$ at a 10-year follow-up as compared to the first year postsurgery. Our series requires observation at a longer term.

Criteria for patient selection is an important issue for DRFT. Patients with GMFCS level I or II are reported to show better prognosis than those with GMFCS level III with regard to timing of peak knee flexion in the swing phase $[6,12]$. The patients who can benefit the most from DRFT at a short and long term are those with baseline PKF less than $64^{\circ}$ and time to PKF more than $80 \%$ [2].

DRFT as part of a single-event multilevel orthopaedic procedure is another important aspect. Although first studies investigated the results of DRFT as a standalone procedure the surgery has been shown to be more effective in combination with lengthening of the medial hamstrings addressing 
the SKG pattern, providing improvement in stance knee extension and preventing tendency for a crouch gait $[4,5]$. Our series included patients treated with the two associated technologies that facilitated less negative effect from pathological activity of the rectus femoris muscle and increase in maximum knee extension during stance phase.

Be Morais et al. reported possible weakness of the quadriceps after DRFT and associated increase in knee flexion throughout stance.The post-surgery increase in knee extension during stance phase was similar between patients who underwent singleevent multilevel orthopaedic surgery with DRFT and without DRFT [6]. Patients functioning at GMFCS level III have a greater risk of increasing knee extension during stance phase. In 2006 Carney et al. [21] described an increase in stance-phase knee flexion in patients who needed walkng assistance or powered mobility (GMFCS level III). Gage et al. [5] related the poorest post-DRFT outcomes to torsion deformities and associated lever arm dysfunction. That is why we support our colleagues who choose to perform DRFT for SKG as part of a single-event multilevel orthopaedic procedure [12, 13].

Our series have shown that correction of orthopadic impairment associated with triceps surae weakness resulting from previous surgeries on the segment (fibromyotomies using the Ulzibat technique [22], open lengthening of the Achilles tendon in children with spastic diplegia) must be provided with DRFT procedure to maintain stance-phase knee kinematics. Technologies applied for our patients included Achilles tendon shortening, talonavicular joint arthrodesis or Evans procedure, shortening of the posterior tibial tendon [23, 24]. Torsional deformities of SKG patients must be addressed as well during single-event multilevel orthopaedic surgery. Accordingly, no case of increased stance-phase knee flexion was recorded in our series after DRFT using the treatment strategies described.

\section{CONCLUSION}

DRFT has been shown to be effective for correction of disturbed knee kinematics in patients with SKG pattern to allow increase in peak knee flexion in swing phase and overall knee range of motion across the gait cycle. The technique can be advocated as part of single-event multilevel orthopedic procedures to improve integral gait parameters. Excessive ankle dorsiflexion in stance phase resulting from previous triceps surae lengthening surgeries must be accurately addressed with DRFT procedure in order to prevent a greater increase in ankle dorsiflexion and iatrogenic crouch gait.

Ethics of publication Written informed consent was obtained from all patients for publication of the findings without identifying details.

Conflict of interest No competing interests were disclosed.

Funding Nothing to disclose.

\section{REFERENCES}

1. Wren T.A., Rethlefsen S., Kay R.M. Prevalence of specific gait abnormalities in children with cerebral palsy: influence of cerebral palsy subtype, age, and previous surgery. J. Pediatr. Orthop., 2005, vol. 25, no. 1, pp. 79-83. DOI: 10.1097/00004694-200501000-00018.

2. Thawrani D., Haumont T., Church C., Holmes L. Jr., Dabney K.W., Miller F. Rectus femoris transfer improves stiff knee gait in children with spastic cerebral palsy. Clin. Orthop. Relat. Res., 2012, vol. 470, no. 5, pp. 1303-1311. doi: 10.1007/s11999-011-2215-1.

3. Miller F., Cardoso D.R., Lipton G.E., Albarracin J.P., Dabney K.W., Castagno P. The effect of rectus EMG patterns on the outcome of rectus femoris transfers. J. Pediatr. Orthop., 1997, vol. 17, no. 5, pp. 603-607. DOI: 10.1097/00004694-199709000-00006.

4. Sutherland D.H., M. Santi, M.F. Abel. Treatment of stiff-knee gait in cerebral palsy: a comparison by gait analysis of distal rectus femoris transfer versus proximal rectus release. J. Pediatr. Orthop., 1990, vol. 10, no. 4, pp. 433-441.

5. Gage J.R., Perry J., Hicks R.R., Koop S., Werntz J.R. Rectus femoris transfer to improve knee function of children with cerebral palsy. Dev. Med. Child. Neurol., 1987, vol. 29, no. 2, pp. 159-166. DOI: 10.1111/j.1469-8749.1987.tb02131.x.

6. De Morais M.C., Blumetti F.C., Kawamura C.M., Lopes J.A., Neves D.L., Cardoso Mde O. Does rectus femoris transfer increase knee flexion during stance phase in cerebral palsy? Acta Ortop. Bras., 2016, vol. 24, no. 1, pp. 27-31. DOI: 10.1590/1413785220162401145765.

7. Asakawa D.S., Blemker S.S., Gold G.E., Delp S.L. In vivo motion of the rectus femoris muscle after tendon transfer surgery. J. Biomech., 2002, vol. 35, no. 8, pp. 1029-1037. DOI: 10.1016/s0021-9290(02)00048-9.

8. Goldberg S.R., Ounpuu S., Arnold A.S., Gage J.R., Delp S.L. Kinematic and kinetic factors that correlate with improved knee flexion following treatment for stiff-knee gait. J. Biomech., 2006, vol. 39, no. 4, pp. 689-698. DOI: 10.1016/j.jbiomech.2005.01.015.

9. Ounpuu S., Muik E., Davis R.B. III, Gage J.R., DeLuca P.A. Rectus femoris surgery in children with cerebral palsy. Part I: The effect of rectus femoris transfer location on knee motion. J. Pediatr. Orthop., 1993, vol. 13, no. 3, pp. 325-330. DOI: 10.1097/01241398199305000-00010. 
10.Ounpuu S., Muik E., Davis R.B. III, Gage J.R., DeLuca P.A. Rectus femoris surgery in children with cerebral palsy. Part II: A comparison between the effect of transfer and release of the distal rectus femoris on knee motion. J. Pediatr. Orthop., 1993, vol. 13, no. 3, pp. 331-335. DOI: 10.1097/01241398-199305000-00011.

11.Nene A.V., Evans G.A., Patrick J.H. Simultaneous multiple operations for spastic diplegia. Outcome and functional assessment of walking in 18 patients. J. Bone Joint Surg. Br., 1993, vol. 75, no. 3, pp. 488-494.

12.Lee S.Y., Kwon S.-S., Chung C.Y., Lee K.M., Choi Y., Kim T.G., Shin W.C., Choi I.H., Cho T.-J., Yoo W.J., Park M.S. Rectus femoris transfer in cerebral palsy patients with stiff knee gait. Gait Posture, 2014, vol. 40, no. 1, pp. 76-81. DOI: 10.1016/j. gaitpost.2014.02.013.

13.Ławniczak D., Jóźwiak M., Manikowska F. Ocena całkowitej predkości liniowej i katowej stawu kolanowego u chorych z postacia spastyczna mózgowego porazenia po operacyjnym leczeniu tzw. "deformacji dźwigniowozaleznych" kończyn dolnych--badanie prospektywne [Assessment of absolute knee joint linear and angular velocity in patients with spastic cerebral palsy after operative treatment of lever arm disfunction deformities--prospective study]. Chir. Narzadow Ruchu Ortop. Pol., 2010, vol. 75, no. 2, pp. 92-97. (in Polish).

14.Read H.S., Hazlewood M., Hillman S.J., Prescott R.J., Robb J.E. Edinburgh visual gait score for use in cerebral palsy. J. Pediatr. Orthop., 2003, vol. 23, no. 3, pp. 296-301.

15.Leardini A., Sawacha Z., Paolini G., Ingrosso S., Nativo R., Benedetti M.G. A new anatomically based protocol for gait analysis in children. Gait Posture, 2007, vol. 26, no. 4, pp. 560-571. DOI: 10.1016/j.gaitpost.2006.12.018.

16.Bell K.J., Ounpuu S., DeLuca P.A., Romness M.J. Natural progression of gait in children with cerebral palsy. J. Pediatr. Orthop., 2002, vol. 22, no. 5, pp. 677-682.

17.Perry J. Distal rectus femoris transfer. Dev. Med. Child. Neurol., 1987, vol. 29, no. 2, pp. 153-158. DOI: 10.1111/j.1469-8749.1987. tb02130.x.

18.Moreau N., Tinsley S., Li L. Progression of knee joint kinematics in children with cerebral palsy with and without rectus femoris transfers: a long-term follow up. Gait Posture, 2005, vol. 22, no. 2, pp. 132-137. DOI: 10.1016/j.gaitpost.2004.08.003.

19.Saw A., Smith P.A., Sirirungruangsarn Y., Chen S., Hassani S., Harris G., Kuo K.N. Rectus femoris transfer for children with cerebral palsy: long-term outcome. J. Pediatr. Orthop., 2003, vol. 23, no. 5, pp. 672-678. DOI: 10.1097/00004694-200309000-00020.

20.Saraph V., Zwick E.B., Auner C., Schneider F., Steinwender G., Linhart W. Gait improvement surgery in diplegic children: how long do the improvements last? J. Pediatr. Orthop., 2005, vol. 25, no. 3, pp. 263-267. DOI: 10.1097/01.bpo.0000151053.16615.86.

21.Carney B.T., Oeffinger D., Gove N.K. Saggital knee kinematics after rectus femoris transfer without hamstring lengthening. J. Pediatr. Orthop., 2006, vol. 26, no. 2, pp. 265-267. DOI: 10.1097/01.bpo.0000218535.89727.47.

22.Shishov S.V., Ivshin V.G. Minimalno invazivnye operatsii na myshtsakh u detei s DTsP. Opyt piatiletnego primeneniia [Minimally invasive surgeries of muscles in children with cerebral palsy. The experience of five-year use]. Vestnik Novykh Meditsinskikh Tekhnologii. Elektronnoe izdanie, 2016, no. 2, pp. 137-141. (in Russian) Available at: https://www.elibrary.ru/download/ elibrary_26423859_32119271.pdf (accessed 23.032018).

23.Popkov D.A., Zmanovskaia V.A., Gubina E.B., Leonchuk S.S., Butorina M.N., Pavlova O.L. Rezultaty mnogourovnevykh odnomomentnykh ortopedicheskikh operatsii i rannei reabilitatsii v komplekse s botulinoterapiei u patsientov so spasticheskimi formami tserebralnogo paralicha [The results of simultaneous multilevel orthopedic surgeries and the early rehabilitation used in complex with botulinum therapy in patients with spastic forms of cerebral palsy]. Zhurnal Nevrologii i Psikhiatrii im. S.S. Korsakova, 2015, vol. 115, no. 4, pp. 41-48. (in Russian) DOI: 10.17116/jnevro20151154141-48.

24.Leonchuk S.S., Chibirov G.M., Popkov D.A. Korrektsiia deformatsii stopy po metodike Evans u rebenka s DTsP v ramkakh odnomomentnogo mnogourovnevogo vmeshatelstva. Sluchai iz praktiki [Foot deformity correction according to Evans technique in a child with cerebral palsy as part of simultaneous multilevel intervention. Case report]. Genij Ortopedii, 2016, no. 3, pp, 77-83. (in Russian) DOI: 10.18019/1028-4427-2016-3-77-83.

Received: 04.02.2020

\section{Information about the authors:}

1. Orhan I. Gatamov, M.D., Ilizarov National Medical Research Centre for Traumatology and Orthopedics, Kurgan, Russian Federation

2. Tamara I. Dolganova, M.D., Ph.D., Ilizarov National Medical Research Centre for Traumatology and Orthopedics, Kurgan, Russian Federation, Email: rjik532007@rambler.ru

3. Dmitrii V. Dolganov, Ph.D. of Biological Sciences,

Ilizarov National Medical Research Centre for Traumatology and Orthopedics, Kurgan, Russian Federation,

Email: Paradigma-DV@rambler.ru

4. Dmitry Yu. Borzunov, M.D., Ph.D.,

Ural State Medical University, Ekaterinburg, Russian Federation,

Central City Clinical Hospital, Ekaterinburg, Russian Federation,

Email: borzunov@bk.ru

5. Georgy M. Chibirov, M.D., Ph.D.,

Ilizarov National Medical Research Centre for Traumatology and Orthopedics, Kurgan, Russian Federation, Email: georgii_chibirov@mail.ru

6. Dmitry A. Popkov, M.D., Ph.D., Professor of RAS, correspondent member French Academy of Medical Sciences, Ilizarov National Medical Research Centre for Traumatology and Orthopedics, Kurgan, Russian Federation, Email: dpopkov@mail.ru 